\title{
O LUGAR DA PARTICIPAÇÃO POPULAR NA GESTÃO DE SAÚDE: MATRIZES CONCEITUAIS E OS RUMOS DA POLÍTICA BRASILEIRA
}

\author{
The place of popular participation into health \\ management: theoretical framework and \\ the Brazilian policy approaches
}

\author{
Eduardo Augusto Werneck RIBEIRO ${ }^{1}$ \\ Raul Borges GUIMARÃES ${ }^{2}$
}

\begin{abstract}
RESUMO
O presente artigo visa discutir a municipalização da saúde no Brasil, tendo em vista as referências da Geografia Política e da Ciência Política, em geral. Para isso, é analisada a questão da participação da comunidade e da forma em que esta foi institucionalizada, bem como suas matrizes doutrinárias. Como irá se demonstrar, a municipalização da política de saúde brasileira envolveu múltiplos atores sociais, delimitando espaços de poder dentro da gestão pública. Ao entendermos que o SUS representa uma gestão territorial, suas implicações na qualidade dos serviços prestados refletem ou refletirão na produção do espaço, assim como no ordenamento territorial da sociedade.
\end{abstract}

\section{Palavras-chave:}

Geografia Política; política de saúde; Conselhos Municipais e participação.

\begin{abstract}
The present article aims at discussing the municipalization of the health in Brazil, taking as reference the Political geography and Political Science. This study analyzes the subject of the community participation, the way in which in was institutionalized, as well as their doctrinaire origins. As it will be shown, the municipalization of the politics of Brazilian health involved multiple social actors in delimiting spaces of power inside of the public administration. At the moment that we understand that the SUS (Brazilian Unified Health System) represents a territorial administration, their implications in the quality of the rendered services contemplate or will contemplate in the space production like this in the territorial order of the society.
\end{abstract}

\section{Key words:}

Political Geography; politic of health; Local Councils and participation.

1 Docente da Uniesp, doutorando do Programa de Pós-Graduação em Geografia da UFPR, colaborador do CEMESPP, e-mail: eduwer@hotmail.com.

2 Professor do Departamento de Geografia da UNESP e Coordenador do CEMESPP, e-mail: raul@prudente.unesp.br. Endereço para correspondência: Roberto Simonsen, 305 - Presidente Prudente-SP - CEP 19060-900. 
RIBEIRO, A. W. R.; GUIMARÃES, R. B. O lugar da participação popular na gestão de saúde: matrizes conceituais...

\section{INTRODUÇÃO}

Tradicionalmente, as pesquisas da Geografia no campo da saúde têm sido divididas em duas grandes vertentes. A primeira delas refere-se aos estudos dos padrões espaciais morbimortalidade e da difusão das doenças no tempo e no espaço. Uma segunda vertente, mais recente, está direcionada à análise da relação entre a oferta de serviços e necessidades da população, o que é um problema complexo: envolve a separação da necessidade e demanda, necessidade sentida pela população e prescrita pelos especialistas, necessidades básicas (freqüentes) e contingenciais (ocasionais), necessidades coletivas e individuais.

O presente artigo tem como objetivo contribuir para o debate dessa segunda vertente, considerando que a saúde pública é um campo fértil para a investigação das relações de poder e da maneira pela qual o Estado é constituído e apropriado no decorrer da política estabelecida e praticada. Especialmente, nos interessa compreender as implicações políticas da implementação dos conselhos municipais de saúde. Tais conselhos são aqui considerados arranjos institucionais do setor abertos à participação da sociedade civil organizada. Em vista disso, iremos observar o seu grau de inovação, na medida em que inclui representantes do governo, dos profissionais e dos prestadores do setor em condição paritária com os representantes dos usuários, escolhidos por associações da sociedade civil. O foco central do trabalho é a reflexão a respeito do lugar dos Conselhos Municipais de Saúde no desenvolvimento da dinâmica social, tornando o município o locus de oportunidade de participação na vida política, econômica e cultural.

\section{DEMOCRACIA E DESCENTRALIZAÇÃO}

É essencial fazer um marco teórico do conceito de democracia e relacioná-la à descentralização do poder, tanto em nivel vertical como em nível horizontal. No primeiro caso, referimo-nos à transferência de poder entre os três níveis de governo, principalmente em relação aos municípios por meio da municipalização da gestão dos serviços. No nível horizontal, referimo-nos ao âmbito da relação Estado-Sociedade, para a qual a participação popular é essencial.
Para essa reflexão é preciso considerar a existência de várias concepções de democracia e mecanismos para a participação popular, presentes em discursos e grupos com interesses opostos.

Na Idade Clássica, o termo democracia era utilizado para designar uma forma de governo no qual o poder político era exercido pelo povo (BOBBIO, 1988a, p.135). A pólis grega (cidade) pode ser considerada como o marco original do conceito. No exercício de direitos e deveres daqueles que habitavam a pólis, havia uma qualificação de seus moradores que era atribuída através da cidadania.

No sentido etimológico da palavra, cidadão deriva da palavra civita, que em latim significa cidade, e que tem seu correlato grego na palavra politikos - aquele que habita a cidade. ${ }^{3}$

Em função dessas origens, a participação ampla e popular era inconcebível. A maioria dos filósofos da Antiguidade e alguns da Modernidade não via com bons olhos a participação popular. Platão, por exemplo, criticava essa forma de governo ${ }^{4}$, pois para ele só os filósofos eram capazes de discutir a essência da ordem política. Por serem os filósofos os possuidores do saber, seriam estes os mais indicados para governar, independentemente da vontade do povo.

Segundo Platão (428-347 a.C.), nós somos prisioneiros do mundo empírico. Filosofar, segundo ele, é conhecer com a razão o mundo primário, ideal, das idéias. A partir do contato com a realidade absoluta, o filósofo pode construir conceitos absolutos, perfeitos. O dever dos governantes é o bem dos governados, mesmo contra a vontade deles, já que a vontade deles está guiada pela ignorância. Quem deveria governar, portanto, seriam os filósofos, pois transcendem as benesses do mundo imediato e possuem um bem muito valioso, os valores intelectuais.

Já Aristóteles (384-322 a.C.), em sua obra Política, descreve e classifica as formas de governo com base em dois critérios. O primeiro é "quem governa" e as respostas podem ser: um só, pouco ou muitos. Portanto, "as constituições podem ser distinguidas conforme o poder resida numa só pessoa (monarquia), em poucas pessoas (aristocracia) e em muitas (politia)". (BOBBIO, 1980e, p. 56)

3 É interessante lembrarmos que, no sentido ateniense do termo, cidadania é o direito da pessoa em participar das decisões nos destinos da cidade através da Ekklesia (reunião dos de dentro para fora) na Ágora. Dentro dessa concepção, surge a democracia grega, na qual somente $10 \%$ da população determinava os destinos de toda a cidade (eram excluídos os escravos, as mulheres e os artesãos).

$4 \mathrm{Na}$ sua obra A república, Platão (428-347 a.C.) distingue seis tipos possíveis de Estado: a forma ideal que ele procura definir (que pode ser tanto a monarquia quanto a aristocracia) e mais quatro formas menos perfeitas: o regime de Creta e Esparta (timocracia), a oligarquia, a democracia e a tirania. 
RIBEIRO, A. W. R.; GUIMARÃES, R. B. O lugar da participação popular na gestão de saúde: matrizes conceituais...

O segundo critério distingue quando o poder é exercido buscando o interesse comum ou quando este se exerce tendo em vista o interesse privado. Desse modo, monarquia é o governo bom de um só, enquanto tirania é o governo mal correspondente a ela; oligarquia é o governo mau de poucos, relacionado à aristocracia, que é a sua forma boa.

E finalmente a politia, que é a forma de governo em que se baseia a vontade popular (o governo bom de muitos) tem como desvio a democracia. A oligarquia visa o interesse dos ricos e a democracia o interesse dos pobres.

A hierarquia aceita por Aristóteles é a timocracia, porque vem depois do reino, que é a forma mais divina. As mudanças que se seguem após a timocracia são cada vez menos graves:

É evidente qual dessas degenerações é a pior e qual vem logo depois. Com efeito, é necessariamente pior a constituição derivada por degeneração da forma primeira, mais divina. Ora o reino o é só de nome, não na realidade; é reino porque quem reina excede extraordinariamente os demais, da mesma forma que a tirania, que é a pior degeneração, é a mais afastada da constituição verdadeira. Em segundo lugar vem a oligarquia (de que a aristocracia difere muito), enquanto a democracia é a mais moderada. (1289a-b) (Aristóteles, apud por Bobbio, op. cit, 58)

A teoria clássica das formas de governo de Aristóteles foi repetida durante séculos sem grandes variações. Segundo Bobbio, "salvo poucas exceções, a tripartição aristotélica foi acolhida em toda a tradição do pensamento ocidental, pelo menos até Hegel, ao qual chega quase extenuada, extornou-se um dos lugares comuns da tratadística política" (BOBBIO, 1994b, p. 320).

Além de nos legar os conceitos básicos descritos, isto é, democracia e cidadania, especificaram seus funcionamentos da seguinte forma na Grécia. Em primeiro lugar, havia um fórum, lugar denominado Ágora (praça pública), onde os cidadãos reuniam-se para discutir assuntos que diziam respeito à coletividade. A partir dos embates de opiniões que ali ocorriam, eram aperfeiçoadas as instituições e as relações entre os cidadãos. Era a democracia direta, na qual os membros da comunidade, dotados de cidadania, reuniam-se em assembléia para deliberar sobre assuntos estatais em pauta.

Enquanto na Antigüidade clássica a maioria dos intelectuais desaprova o governo popular e democracia era uma palavra que representava uma forte reprovação por muitos autores, no século $\mathrm{XX}$, democracia e democrático são palavras que implicam a aprovação da sociedade ou da instituição descrita como tal. Esse aparente consenso em torno da palavra provocou o seu esvaziamento, sendo difícil, desse modo, distinguir uma forma de governo em especial de outra $(\mathrm{BLOCH}$, 1999, p.15).

Hoje não é difícil encontrar nos discursos políticos um consenso - todos se consideram ou se identificam como democratas. Esse resultado reducionista é fruto do esvaziamento conceitual no elemento de participação popular que havia na concepção grega de democracia.

Já no final da Idade Clássica, os Estados encontram-se com grandes territórios, grandes populações e a administração cada vez mais complexa. O exercício da política ganha uma dimensão de natureza técnica mais elaborada que só era acessível a indivíduos mais especializados e se distanciando cada vez mais da população em geral.

Essas mudanças institucionais tornaram os Estados daquela época muito diferentes da realidade ateniense clássica. Dessa forma, as mudanças geopolíticas propiciaram um novo ambiente para se pensar formas de se administrar e ser admitido para conduzir países com dimensões superiores as que eles já tinham conhecimento.

Capitalizando isso, uma série de filósofos começa a desenvolver pensamentos que rejeitam fortemente a democracia no sentido clássico grego. É nesse momento que ocorre a passagem da democracia direta para a democracia indireta.

A transição da democracia direta para a democracia indireta resulta também na separação do poder político que todos os membros da comunidade dotados de cidadania tinham em deliberar plenamente na Ágora. Assim, a República (governo representativo) passou a ser a forma de se conceber a democracia.

Um dos principais elementos de uma república é a delegação da ação governativa a um pequeno número de cidadãos eleitos pelos outros. Um outro aspecto importante é o fato de poder ampliar a sua influência sobre um maior número de cidadãos e sobre uma maior extensão territorial.

A partir dessa idéia, passa-se a acreditar que "a única forma não autocrática de governo possível num grande Estado é o governo por representação". "Como forma de democracia representativa, a república emerge enquanto única democracia possível em determinadas condições de território e de população." (BOBBIO, 1988a, p. 151) 
RIBEIRO, A. W. R.; GUIMARÃES, R. B. O lugar da participação popular na gestão de saúde: matrizes conceituais...

\section{REPRESENTAÇÕES NA DEMOCRACIA MODERNA}

Como a história da democracia passa a coincidir com a dos Estados representativos em vários países europeus, a tipologia das formas de governo simplificase na contraposição entre democracias e autocracias, sendo que o critério distintivo entre eles é a maior ou menor liberdade política. Dessa forma, reagrupa-se monarquia e aristocracia em autocracia, em oposição à democracia. A partir da concepção de democracia representativa, o processo de democratização passa a ser o alargamento do direito ao voto até o sufrágio universal.

Entretanto, mesmo com a consolidação da democracia representativa, o ideal da democracia direta como única forma de democracia nunca desapareceu. Sendo a democracia representativa considerada por alguns grupos como desvio da idéia de governo do povo, mesmo como uma forma imperfeita, ainda é a única possível numa sociedade de classes. (BOBBIO, 1988a, p.154)

Na Idade Média, a idéia de cidadania desaparece na medida em que a pólis e a república, como comunidades políticas, são substituídas pela concepção da coletividade organizada como república christiana, que associa a ordem e a unidade da sociedade cristã à coordenação da Igreja e aos poderes temporais. ${ }^{5}$ Foi esse o princípio basilar da "grande síntese política da Idade Média".

No Renascimento, período em que nascem os conceitos modernos de política e de direitos e deveres do Estado com seus cidadãos, Maquiavel inaugura uma nova tradição no pensamento político. ${ }^{6}$ Primeiro por utilizar a palavra Estado para designar o que os gregos tinham chamado de pólis, os romanos de res publica e que, mais tarde, se transformaria em república. Segundo, porque passou a descrever um Estado totalmente diferente daquele idealizado por Platão.

Para Maquiavel, a gestão do Estado encontra obstáculos na governabilidade ${ }^{7}$ caso se deixe limitar pelos códigos e por muitos que opinem na condução política do Estado em situações difíceis. Nesse caso, o destino poderia ser igual ao da própria Grécia democrática de Platão, ineficaz em organizar uma defesa forte contra as invasões que a sucumbiram.
Contudo, avisa o autor, tais atributos deveriam ser sempre utilizados em função do bem comum e não em detrimento deste para favorecimento pessoal da autoridade estatal. Afinal, o Príncipe "deve tratar amistosamente o povo" ${ }^{8}$ e só deve usar de severidade quando sua segurança é ameaçada ou quando dela resultar benefícios para os cidadãos. Caso contrário, a severidade levará à sua queda.

Embora um pensador dos tempos modernos, Rousseau vai buscar inspiração nos valores da cidade antiga para fundamentar a sua idéia de participação popular. Mais precisamente, a natureza e limites da integração do indivíduo na sociedade, fundada, naqueles termos, pelo pacto social.

Diferente dos outros autores da época, sua teoria é marcada pela exigência de uma participação direta do povo no legislativo. Ele não admite a representação da vontade de um cidadão para o outro.

A vontade só será geral se tiver a participação de todos os cidadãos de um Estado, em uma arena de debate político. Assim haverá a garantia efetiva do bem comum e dos direitos dos cidadãos.

Andrioli (2003), ao analisar Rousseau, entende que todos precisam estar em condições de igualdade para haver democracia. Nenhum ser humano poderá ser autoridade diante dos demais e as convenções, criadas por todos, são as bases de toda autoridade legítima.

O interesse de um representante sempre é privado e não poderá expressar o que os outros têm a dizer. Rousseau refere-se à representatividade como uma idéia absurda, originária da sociedade civil corrompida, não podendo haver democracia se essa não for direta e as leis que não forem ratificadas pelo próprio povo serem consideradas nulas.

Para Bobbio (1987c), a Revolução Francesa representou a primeira vez que houve exercício do direito do povo de decidir seu próprio destino (direito de liberdade em um de seus sentidos). Ou seja, o direito que tem um povo de não ser impedido por outras forças de dar a si mesmo uma Constituição Civil. Mais tarde, essa constituição não passou de expressão retórica, materializada pela Declaração Universal dos Direitos dos Homens de 1789.

Na modernidade, consolidou-se a forma de participação da população na administração do Estado,

5 Ambos instituídos por Deus para manter, sobre a terra, a paz e a justiça.

6 Neste momento, é importante lembrarmos sobre o nexo político da cidadania entre a população, o Estado e o seu território, que no passado teve como referência a cidade (pólis) ou Cidade-Estado, deslocou-se na democracia moderna (contratual) para o Estado-Nação. Sua qualidade passou a ser dada pela nacionalidade e os seus limites territoriais pelos contornos geográficos das fronteiras nacionais.

7 Trata-se de um conceito amplo, entretanto, aqui, apenas o entendimento de poder governar.

8 Maquiavel, N. O príncipe, Capítulo IX, p. 73, 2004. 
RIBEIRO, A. W. R.; GUIMARÃES, R. B. O lugar da participação popular na gestão de saúde: matrizes conceituais...

mas esta perdeu seu sentido originário. As estruturas administrativas que deveriam ser as representantes da vontade da maioria ou a participação direta do cidadão foram substituídas por uma participação representativa do desejo público.

Na nova ordem política que se instaurou, as pessoas passaram a ser iguais perante a lei, erigida como padrão de igualdade entre todos os seres humanos. Mas não aconteceu uma modificação das condições materiais das classes populares, e a liberdade, desvirtuada na prática, passou a ser utilizada pelo homem burguês como capacidade ilimitada de exercer a sua iniciativa, a sua criatividade e os seus direitos individuais.

Marx, relatando a experiência da Comuna de Paris (1871), segundo Bloch (1999), apud Bottomore (1988, p. 98), por sua vez, afirmou seu compromisso com a democracia direta. A partir da crítica rousseauniana ao princípio da representação, origina-se a concepção inicial de Marx sobre a democracia. Para ele, a verdadeira democracia implica o desaparecimento do Estado e, assim, o fim da separação entre o Estado e a sociedade civil. Desaparece, desse modo, a divisão entre governantes e governados.

Em contrapartida, as diferenças aprofundadas pelo Estado liberal com o capitalismo industrial também influenciou o pensamento político. Segundo essa perspectiva, o Estado burguês deveria ser substituído pelo Estado proletário ${ }^{9}$, que aplainaria as desigualdades sociais.

De acordo com o proletariado ${ }^{10}$, o Estado liberal era extremamente individualista, injusto e desigual, e converteu a representação popular em um instrumento sem qualquer participação nas arenas decisórias. A separação entre Estado e Sociedade foi radicalizada pelo individualismo liberal, que ampliou as fronteiras do mercado e reduziu as do político, despolitizando a cidadania.

Os movimentos de base passaram a questionar o fosso que se alargara entre os postulados de igualdade e liberdade para todos e a trágica situação vivida pelos trabalhadores e pela população em geral, reivindicando a real efetivação de tais direitos declarados.

Por força das pressões da sociedade, cada vez maiores no começo do século $X X$, acabou ocorrendo a transição do modelo liberal clássico para o Estado So- cial, mudança esta perceptível pelo paulatino abandono da atitude de um Estado abstencionista por uma posição intervencionista propiciadora de meios de acesso aos bens sociais.

Nas primeiras décadas do século XX, a Revolução Mexicana - de 1917 (com sua Constituição socialista), e a Constituição de Weimar - na Alemanha de 1919 (ressaltando os direitos sociais), ampliam a realidade da dimensão dos direitos humanos, declarados em 1789. Os direitos deixaram de ser entendidos apenas como direitos individuais e passaram a abarcar - ainda que restritamente, em muitos lugares - os direitos coletivos de natureza social.

A crise econômica de 1929 trouxe a necessidade de refletir sobre um Estado que equilibra a economia com uma proposta específica. Surgiu, então, a crença de que os indivíduos que não têm direitos a conservar são os que mais precisam do Estado.

Finalmente, com o fim da II Guerra Mundial, o problema dos direitos básicos da pessoa humana foi posto mais uma vez na ordem do dia. Com a Carta das Nações Unidas, assinada em 26 de junho de 1945, criou-se uma organização internacional (a ONU) voltada à permanente ação conjunta dos Estados na defesa da paz mundial, incluída aí a promoção dos direitos humanos e das liberdades públicas.

Com tais propósitos, ao menos em tese, a noção dos Direitos Humanos deixou de ser um compromisso de cada país, individualmente, para passar ao status de princípio constitucional, recepcionando parâmetros internacionais, a inspirar as ações dos membros - fundadores ou futuros - da organização. Como a experiência já havia deixado claro que não pode haver paz sem justiça social, decidiu-se por uma Resolução específica sobre tais direitos, vagamente referidos na Carta.

$\mathrm{Na}$ terceira sessão ordinária da Assembléia Geral da ONU, realizada em Paris, a 10 de dezembro de 1948, foi aprovada a Declaração Universal dos Direitos Humanos, presidida pelo brasileiro Oswaldo Aranha. A declaração proclamou os direitos e liberdades fundamentais "como o ideal comum a ser atingido por todos", e tratou de exaustivamente enumerá-los com a finalidade de permitir-lhes melhor proteção jurídica, partindo do postulado geral de que "todos os homens nascem livres e iguais em dignidade e direitos (...) e devem agir em

9 A gestão do proletariado só é compreendida na gestão da burguesia. O processo de transformação do camponês em proletário teve circunstâncias distintas entre paises.

10 Há diversas correntes políticas de esquerda que discutem o caráter do Estado capitalista. Há uma discussão entre a social democracia, anarquista e socialista a respeito do Estado. Num outro modo de produção há a teoria do Estado de Lênin. 
RIBEIRO, A. W. R.; GUIMARÃES, R. B. O lugar da participação popular na gestão de saúde: matrizes conceituais...

relação uns aos outros com espírito de fraternidade", como reza o primeiro artigo.

Os artigos da Declaração trazem características como a certeza dos direitos (com a prévia e cristalina fixação de direitos e deveres), a segurança dos direitos (impondo normas para sua respeitabilidade) e a possibilidade dos direitos (exigindo os meios para todos terem acesso ao gozo destes).

Com a Declaração, esses direitos se projetaram acima do patamar de pretensões individuais e coletivas perante o Estado, cabendo a este o papel de agente promotor das garantias e dos direitos chamados sociais. Esse momento da história ficou conhecido como o Estado do Bem Estar Social ou Welfare State.

Estabelecidos os aspectos legais sobre os direitos dos homens, a relação entre sociedade civil e governo também desenvolveu uma complexidade maior sobre o pensamento de representação popular e seus instrumentos.

Nesse modelo, transferiu-se para o Estado e sua intervenção na sociedade o pólo principal da cidadania. Aos direitos naturais e políticos, centrados no indivíduo e na sociedade, acresceu-se direitos sociais que são, ao mesmo tempo, obrigações do Estado para com o cidadão.

Novos instrumentos precisavam ser repensados para se representar a soberania popular. Os homens com direitos passaram a ser cidadãos modernos que exercem sua cidadania, reforçando o reposicionamento de governantes democráticos não apenas por serem a fonte de sua legitimidade, mas também por serem portadores dos mesmos direitos.

Quando garantidos, esses direitos dão poder ao cidadão e limitam os governantes. Assim, surgem novas formas de participação popular, oferecendo possibilidades de administrar e legitimar a democracia representativa. Entre tais possibilidades, a municipalização surge não apenas como um instrumento, mas também como uma escala da representação e gestão.

\section{A MUNICIPALIZAÇÃO E A PARTICIPAÇÃO: TENDÊNCIAS MUNDIAIS}

Com as mudanças estruturais decorrentes dos anos 70, desenvolvem-se em muitos países estudos sobre a reorganização da gestão territorial dos processos econômicos, sóciopolíticos e administrativos. O grande volume de reflexões foi proveniente da Europa, onde o
Estado provedor estava passando por reformulações conceituais, buscando redesenhar um projeto de relação Estado-Sociedade. Nesse caso, segundo Fleury:

Um projeto de democracia, no qual a gestão pública social seja um dos principais mecanismos promotores da inserção dos cidadãos em uma nova comunidade política, que se expressa em novos formatos para a relação Estado/Sociedade. (FLEURY, 1997, p. 23)

Diante da diversidade, encontra-se um eixo centralizador nas suas reflexões a respeito do território e sua gestão pelo Estado do Bem Estar, que estava em crise. Acredita-se que a centralização da administração dificultaria o desenvolvimento de políticas sociais eficazes, pois enfraqueceria muito as necessidades locais em nome da centralização de recursos e competências em favor do governo central.

Para Netto (1991), as experiências da Itália, da França e da Espanha ajudaram a expandir o pensamento sobre a municipalização e a democratização do poder. Em função disso, vamos nos ater a esses exemplos a seguir.

No caso da experiência italiana, o autor analisa o processo que ocorreu em Bolonha. Segundo ele, foi de lá que irradiou a gestão a partir da descentralização municipal, em 1963.

Rapidamente, a iniciativa de Bolonha estendeuse pelos municípios governados pela esquerda, principalmente no norte da Itália. Em 1976, o governo italiano, por meio da lei $278^{11}$, deu suporte legal à experiência rica e bem-sucedida.

Legalmente, a regionalização do Estado na Itália já encontrava subsídios na Constituição de 1948, apesar de não se verificar nenhum avanço sobre o tema até então. Vinte anos depois, por meio de eleições regionais (provinciais e municipais), foram criadas novas estruturas que fomentaram um novo pensar sobre o papel da municipalidade.

Naquele momento, a Itália tinha uma herança de um passado oligárquico e fascista e da falta de alternância de poder. O país contava com mais de 8.000 municípios em uma esfera hierárquica administrativa menor, e de 90 províncias na esfera intermediária. No topo da hierarquia administrativa estava o governo central. Os níveis administrativos municipais e provinciais foram concebidos no século XIX com fins militares e de ordem pública periférica à do governo central. 
RIBEIRO, A. W. R.; GUIMARÃES, R. B. O lugar da participação popular na gestão de saúde: matrizes conceituais...

Esses fatos impulsionaram as administrações das localidades periféricas a buscarem mudanças na estrutura territorial administrativa. Assim, com o incremento desses níveis institucionais tornou-se viável não só a possibilidade de se descentralizar o Estado, mas também a de se estruturar uma democratização e a reforma de um Estado cheio de vícios.

O caso da França, Netto (1991) diz ser um caso raro. Por ser um país politicamente desenvolvido, apresentava um grau de centralização elevado, devido à herança do período napoleônico.

Segundo o autor, o debate polarizou entre a centralização e descentralização da administração regional. A discussão do tema procurou denunciar o quanto o processo de centralização na condução da acumulação capitalista exigiu formas específicas de relação entre as instituições de financiamentos de recurso centrais e as administrações locais.

O ponto de partida foi uma lei de $1982^{12}$ (a lei da descentralização), pela qual foram definidos os direitos e as liberdades dos municípios, departamentos, regiões e redimensionamento dos três níveis da administração (NETTO, apud MASSOLO, 1988).

As críticas à descentralização estavam apontando que essa prática estaria escondendo a responsabilidade do governo central e decisões que eram tomadas nos bastidores que favoreciam a reprodução do capital monopolista na nova divisão territorial da política. Os recursos eram escassos e todos estavam centralizados devido à crise que o Estado francês passava naquele momento.

Devido à formação espacial da França, com base em mais de 36.000 municípios, 4.000 cantões, 96 departamentos e 22 regiões, havia a possibilidade do aumento da diferenciação econômica entre as regiões. Assim, o pensamento da municipalização não era de racionalização dos esquemas de ordenação territorial e sim o de ser um instrumento mais eficiente na utilização de recursos.

$\mathrm{Na}$ Espanha, diferentemente da França, os processos de descentralização produziram resultados mais concretos com os temas descentralização e participação popular. Isso se deve ao fato de que o processo de democratização do Estado espanhol, no início da década de 1980, não pode ser explicado sem levarmos em conta a importância de demandas da população local e das populações regionais na luta contra a ditadura de Franco.
Segundo o mesmo autor, na reorganização da sociedade espanhola, a vontade em recuperar elementos de identidade e vida coletiva coincidiu com as demandas das regiões e localidades. Sem esses ingredientes, não se poderia entender o caráter pacífico, descentralizado e consensual do processo de democratização política na Espanha.

O desafio era pensar na complexidade de um sistema de gestão que pudesse dar voz à diversidade nacional e à vasta gama de conjuntos ou subsistemas regionais e locais de representação política. Foi assim, então, que em 1985 foi aprovada a Ley Reguladora de las Bases del Regimen Local ${ }^{13}$. A lei estabeleceu as hierarquias, as competências, a participação e a descentralização das comunidades autônomas e dos municípios, assim resgatando o caráter democrático da vida local em comparação ao regime do governo anterior.

\section{REFLEXOS NO BRASIL}

Tanto as matrizes conceituais quanto as experiências européias citadas nos mostram que a criação de mecanismos de representação e de fortalecimento da participação popular têm sido um enorme desafio. Principalmente no âmbito de sua formulação e implantação. Hoje, um exemplo de uma instituição bastante difundida e que se mostra como resultado do debate acima descrito, os Conselhos de Saúde Municipais implementados no Brasil, se mostram como um componente importante para a reflexão que iremos propor.

Objetivo de luta anterior à promulgação da Constituição Federal de 1988, o Movimento Sanitário já havia colocado a discussão da Saúde como parte da conquista da democracia e proposto a criação do Sistema Único de Saúde, desde 1978. Esse movimento tinha a intenção de construir uma nova política de saúde que fosse efetivamente democrática, considerando a descentralização, a universalização e a unificação como elementos essenciais para a reforma do setor.

O movimento tomou corpo e força representativa no Congresso Constitucionalista e ficou conhecido pela sua atuação direta e indireta na Comissão Mista de Reforma Sanitária, por meio do delineamento das bases de um sistema de saúde público e gratuito, cuja concretização se efetuará praticamente no início da década de $1990^{14}$. O marco regulatório desse processo foram

12 Lei n. 82-213 du 2 mars 1982 relative aux droits et libertés des communes, des départements et des régions.

13 Ley 7 - Reguladora de las Bases del Régimen Local, de 2 de abril de 1985.

14 Foram criadas as Leis Federais 8080 e 8142, de setembro e dezembro de 1990, respectivamente, referentes à regulamentação e à formas de ações de Saúde que o Estado deve seguir baseado nas diretrizes da Constituição e com a Lei Orgânica da Saúde. 
RIBEIRO, A. W. R.; GUIMARÃES, R. B. O lugar da participação popular na gestão de saúde: matrizes conceituais...

as Leis Federais 8080 e 8142 de setembro e dezembro de 1990, respectivamente, referentes à regulamentação e às formas de ações de Saúde que o Estado deveria seguir baseado nas diretrizes da Constituição e na Lei Orgânica da Saúde.

$\mathrm{Na}$ análise de Figueredo (2001), a Constituição confere novos papéis e espaços para a atuação das organizações da sociedade civil. Entre esSes papéis, destacam-se:

a) cooperação no planejamento municipal (art. 29, X da CF);

b) presença assegurada na realização de audiências públicas com as comissões permanentes e temporárias do Congresso Nacional e suas Casas (art. $58, \S 2^{\circ}$, II da CF);

c) legitimidade ativa em denunciar irregularidades ou ilegitimidades perante o Tribunal de Contas da União (art. 74, § $2^{\circ}$ da CF);

d) participação na gestão da Seguridade Social (art. 194, VII da CF);

e) participação nas ações e serviços públicos da saúde (art. 198, II da CF).

Verifica-se que a Constituição estabeleceu a possibilidade de adotarmos uma democracia participativa na esfera social, atribuindo papel de destaque às associações em variadas instâncias de decisão e de consulta. Essa decisiva inovação institucional decorreu, contudo, das lutas políticas e sociais que tiveram início ainda na década de 1970 e que serviram de parâmetros para os encaminhamentos políticos adotados pela reforma sanitária.

\section{POR UM ROTEIRO DE ANÁLISE GEOGRÁFICA DA GESTÃO MUNICIPAL DE SAÚDE}

Em vista das considerações acima, o campo da saúde suscita novas questões de Geografia Política a respeito das coalizões e articulações verticais e horizontais que tais programas podem estar viabilizando no momento atual. Em resumo, há profundas implicações de Geografia Política na saúde pública. entre elas, destacamos:

- a definição de quem exerce poder e disputa a agenda da política de saúde pública, interferindo nos poderes da soberania da naçãoEstado;

- a compreensão dos projetos políticos dos atores sociais que atuam na saúde pública, considerando contradições e conflitos de interesse no interior do Estado;
- a delimitação de espaços de poder, bem como as ações coletivas adotadas e sua relação com determinados padrões de espacialidade da política, elaboradas seja nas matrizes conceituais ou nas práticas em saúde pública.

Para identificar as forças de cooperação e conflito no campo da saúde, retomemos o exemplo das cidades brasileiras. A consolidação do Sistema Único de Saúde (SUS), desde o final da década de 1980, tem fortalecido o poder local e incrementado os investimentos na expansão dos equipamentos, visando uma melhor cobertura dos serviços de saúde no tecido urbano.

Mas a política de saúde não interfere apenas na configuração territorial das cidades. Ela também é uma forte indutora da produção simbólica do urbano (GUIMARÃES, 2000). Não se trata só de uma rede de equipamentos conectados aos fluxos do espaço urbano, mas de um conjunto de atores sociais que a freqüentam buscando um objetivo ou cumprindo uma tarefa bem localizada territorialmente. Cada um desses atores (corpo técnico dos hospitais e unidades básicas de saúde, usuários dos serviços, lideranças das associações de moradores, entre outros) ocupa uma posição relativa numa rede de múltiplas relações de controle, de vizinhança, de distanciamento e de aproximação, que cria e recria lugares de poder, nos termos estudados por Raffestin (1993).

É por causa disso que a rede de serviços de saúde não é neutra, mas impregnada de mensagens e valores definidos no campo social e político, guardando uma estreita relação com a produção da escala geográfica urbana: esfera diária do mercado de trabalho, mediada pelo mercado imobiliário e pela sociedade de consumo (SMITH, 2000).

Os resultados obtidos na pesquisa de mestrado intitulada $A$ análise geográfica dos gastos municipais em saúde (RIBEIRO, 2005) permitem pontuar algumas reflexões sobre aquelas discussões e futuras avaliações do processo de implementação e consolidação dos Conselhos Municipais de Saúde enquanto instrumento de gestão de políticas públicas.

Entendemos que o SUS gerido na esfera municipal é um modelo de gestão estratégica de um serviço essencial para uma grande parcela da população brasileira. Contudo, um dos grandes problemas da implementação do modelo que o SUS propõe é sem dúvida a desinformação e a falta de conhecimento de quem governa.

Do ponto de vista geográfico, o SUS representa uma gestão territorial, pois suas implicações na qualidade dos serviços prestados refletem ou refletirão na organização espacial, assim na sociedade. 
RIBEIRO, A. W. R.; GUIMARÃES, R. B. O lugar da participação popular na gestão de saúde: matrizes conceituais...

A partir do que se tem verificado em municípios do porte de Presidente Prudente - SP, uma temática relevante que se coloca para a investigação é a da questão da fragilidade e desarticulação dos Programas Municipais de Saúde e a sua dificuldade de articulação com as políticas públicas que estão sendo implementadas, tanto na esfera municipal como na federal. ${ }^{14}$

Como reflete Jannuzzi (2001), é comum encontrarmos na literatura especializada de avaliação referências a dimensões desejáveis de desempenho de organizações e programas avaliados. São largamente utilizados como indicadores de programas de saúde os termos efetividade, eficiência e eficácia. Assim, os programas sociais serão somente eficazes se forem antes efetivos e eficientes, pois os objetivos pretendidos destes também são estruturados pela condução e objetivos efetivos dos programas.

Ainda nessa pesquisa, a análise das respostas dos gestores nas entrevistas realizadas traz o reconhecimento da falta de pessoal com preparo técnico como sua maior dificuldade, remetendo-nos a uma matriz discursiva platônica, conforme os pressupostos conceituais desenvolvidos na primeira parte deste texto. Ao mesmo tempo, pode-se compreender que certa concepção rousseauniana deriva outras dificuldades também citadas pelos gestores, entre as quais estão as que correspondem à própria visualização da formulação da política no interior da cidade.

Vamos desenvolver melhor essa idéia. Para isso, é preciso considerar a leitura que se faz da produção do espaço urbano.

Existe uma vasta produção bibliográfica sobre a produção do espaço urbano. Carlos, por exemplo, ao refletir sobre a dimensão da desigualdade no espaço intra-urbano, ensina:

Podemos analisar o urbano de dois pontos de vista: o do produtor, que necessitará de equipamentos de infra-estrutura, de informação, de inovação, de amplas instalações e o do consumidor, que usará o espaço fundamentalmente por questões de sobrevivência: o habitar e o trabalho, mas que para tal necessita de equipamentos de lazer, oferecimento de determinados bens e serviços coletivos, de cultura etc. Em suma, cada um desses personagens tentará usufruir desse espaço do melhor modo possível para a satisfação de suas necessidades, seja a de produzir ou a de consumir; mas, se levarmos em conta que o produzir não exclui o consumo, e o vice-versa, a análise nos colocará outras questões (...). (CARLOS, 1994, p. 53)
Dessa forma, a reprodução do espaço urbano recria constantemente as condições gerais a partir das quais se realiza o processo de reprodução do capital. A cidade aparece como um bem material, consumida de acordo com as leis de reprodução do capital. Mas, por outro lado, a cidade não é simples condição objetiva de vida, ela supõe condições de direção, gestão, atividades sociais, políticas, religiosas, etc. Pode-se dizer que em certo sentido é também cultura: e guarda a dimensão do humano. Todavia, ela se produz de forma vinculada à propriedade privada, que se materializa na segregação espacial.

Indo além, Santos aponta que:

(...) a cidade em si, como relação social e como materialidade, torna-se criadora de pobreza, tanto pelo modelo socioeconômico de que é o suporte como por sua estrutura física, que faz dos habitantes das periferias (e dos cortiços) pessoas ainda mais pobres. A pobreza não é apenas o fato do modelo socioeconômico vigente, mas, também, do modelo espacial (....). (SANTOS, 1993, p. 10)

Para Correia (1993), por sua vez, ao olharmos o intra-urbano, encontraremos uma cidade fragmentada, articulada, reflexo e condicionante social, a cidade é também o lugar onde as diversas classes sociais vivem e se reproduzem. O espaço da cidade é:

(...) o cenário e o objeto das lutas sociais, pois estas visam, afinal de contas, o direito à cidade e à cidadania plena e igual para todos - é um produto social, resultado de ações acumuladas através do tempo, e engendradas por agentes que produzem e consomem espaço (...). (1993, p. 11)

Ou seja, em vista da natureza da produção do espaço urbano na sociedade contemporânea, a gestão das políticas públicas precisa considerar as diferenças. A resposta de tal desafio na formulação da política de saúde foi rousseauniana, uma vez que propôs a legitimação dos diferentes, como se fosse possível impedir a sobreposição dos interesses individuais ao coletivo.

É por causa disso que, aparentemente, o mecanismo de identificação sobre a alocação dos recursos financeiros num sistema urbano complexo, como são as cidades brasileiras, estimulam a visualizar estas como números homogêneos.

É lógico que o aumento no número de consultas médicas, ou até mesmo a construção de alguma

14 O Inicialmente foi realizado estudo comparativo com as cidade de Presidente Prudente, Marília, São José do Rio Preto e Araçatuba -SP, nos anos entre 1995 e 2003. A seguir, exploramos o caso de Presidente Prudente. 
RIBEIRO, A. W. R.; GUIMARÃES, R. B. O lugar da participação popular na gestão de saúde: matrizes conceituais...

unidade básica de saúde em um bairro carente para aquela comunidade que luta para sua implantação, é um avanço e uma melhoria no serviço de saúde. Contudo, o aumento de gastos com saúde per capita não tem uma relação direta com a melhoria da condição de saúde e a diminuição das iniquidades intra-urbanas (RIBEIRO, 2005).

Tais conclusões têm implicações imediatas na forma de se pensar políticas públicas de saúde, porque indicam a necessidade de estabelecer relações criativas entre a produção do espaço, as matrizes conceituais da política e as experiências práticas.

\section{DESAFIOS PARA PESQUISAS FUTURAS}

Houtzager et al. (2004, p. 4) destaca que a literatura sobre a descentralização democrática tem uma perspectiva controvertida no debate a respeito dos mais variados elementos da sociedade civil, ou dos cidadãos comuns que ocupam diferentes posições na comunidade, de ter acesso e utilizar os novos arranjos institucionais.

A participação dos cidadãos comuns nas associações civis, nas eleições e nos movimentos sociais nos países mais ricos tem sido problematizada e teorizada de perspectivas diversas, faltando avançar esse campo no Brasil.

É fundamental perceber o conjunto de forças em disputa e problemas que estão por trás dos acontecimentos. Tão importante quanto apreender o sentido de um acontecimento é perceber quais as forças, os movimentos e as condições que as geram.

Em uma leitura análoga, Souza (2000), ao analisar a participação popular como experiência no orçamento participativo de Porto Alegre - RS, afirma que, à medida que se avança a complexidade das relações de co-gestão, o questionamento de todo modelo da democracia representativa fica mais evidente, embora alguns grupos tendam a ver no orçamento participativo um simples "tempero", um simples "enriquecimento" ou "complemento" do modelo da democracia representativa. Outros, contrariamente, não desejam esconder a tensão essencial entre participação direta e "representação". (2000, p. 46)

Ao tratar sobre as possibilidades de se construir uma política pública que possa realmente ser acessível à população, necessário se faz refletir a respeito da forma com que a participação popular é institucionalizada no sistema político local.
No caso dos orçamentos participativos, embora sejam mecanismos criados para que os cidadãos possam participar do processo de definição de prioridades e aproveitamento dos recursos públicos, o que se verifica é apenas o empenho residual de pequenas verbas públicas, sem mudanças de prioridades no conjunto dos gastos públicos. Isso se dá sob a alegação de que o restante já está comprometido com manutenção e pagamento de pessoal. Não chega a se concretizar a participação cidadã na formulação e implementação de políticas públicas no município.

Diferentemente são os casos dos Conselhos Municipais de Saúde gestores do Sistema Único de Saúde (SUS). Os Conselhos têm poder deliberativo sobre os recursos da saúde do município ${ }^{15}$, através do fundo municipal de saúde, conforme exemplifica a figura abaixo:

\section{FIGURA 1: FLUXO DE FINANCIAMENTO DO SUS}

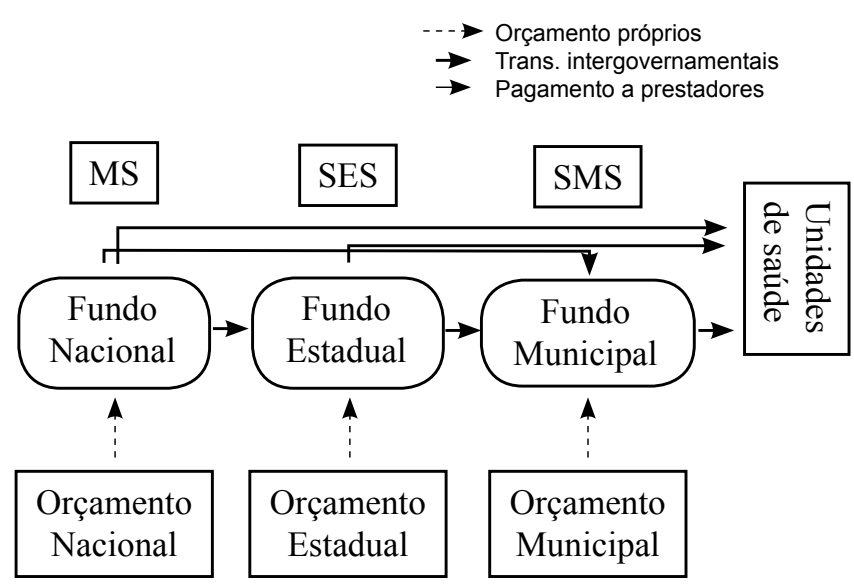

FONTE: Datasus e org. Ribeiro

A intensa habilitação de estados e municípios em modalidades avançadas de gestão, ocorridas a partir dos anos 90, gerou um expressivo aumento das transferências diretas de recursos do Fundo Nacional de Saúde para os fundos estaduais, que, por sua vez, repassam para os fundos municipais.

Além das transferências do Fundo Nacional de Saúde, os fundos estaduais e municipais recebem aportes de seus próprios orçamentos. Alguns estados, através das Secretarias Estaduais de Saúde (SES), promovem repasses de recursos próprios para os Fundos Municipais de Saúde, de acordo com regras definidas no âmbito estadual, assim ocorre também com as Secretarias Municipais de Saúde (SMS). O Conselho Municipal é o gestor do Fundo Municipal, quando o município está habilitado com a gestão plena do Sistema de Saúde. 
RIBEIRO, A. W. R.; GUIMARÃES, R. B. O lugar da participação popular na gestão de saúde: matrizes conceituais...

É importante ressaltarmos que o nível federal ainda é o responsável pela maior parcela do financiamento do SUS, embora a participação dos municípios venha crescendo ao longo dos últimos dez anos e haja a perspectiva de que a parcela dos recursos estaduais no financiamento do sistema aumente significativamente em decorrência da aprovação da EC-29. (RIBEIRO, 2005, p. 39)

Dessa forma, não haverá riscos em se pensar que o SUS é democrático por apenas assegurar a participação popular na gestão dos recursos, mas sim necessitando rever que esta é apenas uma das várias formas de participação política da sociedade. Ou seja, não negamos o avanço que o SUS representa, mas ainda há muito o que avançar.

\section{CONSIDERAÇÕES FINAIS}

A participação ou a cidadania vem etimologicamente e historicamente de cidade, compreendida no sentido clássico de sociedade política. Os cidadãos eram os membros livres da sociedade e se articulavam e participavam da vida pública, tendo como objetivo o interesse coletivo. Nesse sentido, cidadania e cidadão referem-se à participação da vida na cidade, entendida como o espaço público para as decisões coletivas. (BENEVIDES,1994, p. 2)

No Brasil, país marcado por desequilíbrios e desigualdades, deve-se ressaltar que participação da sociedade nas arenas de decisão política, entretanto, não garante por si só que sua implementação se dará democraticamente no contexto da cidadania ativa.

Para Dowbor (1996), a representação pressupõe o princípio de liberdade e a participação está baseada no princípio de igualdade. Muitos autores privilegiam um dos princípios em detrimento do outro. Entretanto, uma verdadeira democracia deveria articular a liberdade e a igualdade, o conjunto das regras com os resultados, o individual e o coletivo, a representação e a participação.

A Constituição de 1988 traz fundamentos legais para que as cidades brasileiras possam apresentar uma variedade de instituições como mecanismos para a participação do cidadão, com a intenção explícita de ampliar a institucionalização democrática oferecendo, uma vez implantadas, novas oportunidades de participação direta no desenho das políticas públicas e na regulação da ação governamental.

O sistema de saúde nacional traz desafios importantes para o entendimento das dinâmicas estabelecidas nos vários níveis organizacionais e institucionais. Acordos, arranjos e jogo de interesses entre prestadores de serviço, governo e sociedade só podem ser dimensionados e analisados se conseguirmos visualizar, ou até mesmo desvendar, o que se passa no interior dessas estruturas.
Os efeitos da desregulamentação da economia, a flexibilização do trabalho ou até mesmo os novos arranjos da vida social (a desestruturação da família, como unidade celular na sociedade, por exemplo) fazem recuar direitos sociais básicos em todo o mundo e ameaçam direitos civis elementares, consagrados como direitos universais do homem.

Um debate interessante tratado por Machado (1995) mostra a preocupação de pesquisadores em saúde coletiva para equacionar essa proposta. Há, segundo essa autora, sem dúvidas, um crescimento cada vez maior de estudos e pesquisas sociais com enfoque na leitura de atores políticos para fomentar o entendimento mais detalhado dos processos políticos expressos nas múltiplas e variadas escalas de atuação e produção.

Em uma época na qual se busca a eficiência do planejamento e da gestão de políticas públicas de inserção social, pensar o Estado perante os interesses do coletivo no desenvolvimento social de uma grande parcela da população sem uma cidadania efetiva se apresenta como experiência ousada.

Gostaríamos de propor uma outra leitura. Existe a possibilidade clara de se pensar o coletivo participando efetivamente nas decisões políticas do Estado (em todas as suas esferas administrativas). Os Conselhos Municipais de Saúde brasileiros são uma realidade. Uma realidade, entretanto, pouco aproveitada e aperfeiçoada tecnicamente.

Penetrar mais a fundo na compreensão desse promissor tipo de experiência em gestão urbana exige o enfrentamento de diversas questões ainda não contempladas ou insuficientemente contempladas. Muitas dessas questões recordam, de modo evidente, a enorme relevância da dimensão da participação popular em novos instrumentos de decisão e participação em arenas políticas para o entendimento da dinâmica desse processo, a qual vem sendo negligenciada por muitos de seus interlocutores.

$\mathrm{O}$ que se pretendeu com o presente texto não foi oferecer propriamente uma discussão pormenorizada do fenômeno da participação popular via Conselhos Municipais de Saúde, mas sim colaborar para construir uma estratégia de abordagem do assunto sob um ângulo que destaque 0 fenômeno político e o integre com as demais dimensões sociais. De qualquer forma, a idéia relativa à instauração de uma nova ordem de cidadania é condizente com o aprofundamento da democracia participativa que, no nosso entender, os Conselhos Municipais de Saúde estariam fomentando. É preciso pesquisar sob quais condições e em quais localidades a participação popular efetivamente se coloca no processo de tomada de decisão com base nesses Conselhos Municipais. 
RIBEIRO, A. W. R.; GUIMARÃES, R. B. O lugar da participação popular na gestão de saúde: matrizes conceituais...

\section{REFERÊNCIAS}

ANDRADE, Regis de Castro. The individual and the citizen in the history of ideas (with an essay on Machiavelli). Lua Nova, n. 57, p. 33-71, 2002.

ANDRIOLI, Antonio Inácio. A democracia direta em Rousseau. Revista Espaço Acadêmico. v. 2, n. 22. ago. Disponível em: Web $<$ http://www.espacoacademico.com.br/22and_rousseau.htm> Acesso em 20/ 3/ 2002.

BRASIL. Lei n. 8.080, de 19 de setembro de 1990.

BRASIL. Lei n. 8.142, de 28 de dezembro de 1990.

BRASIL. Ministério da Saúde. Resolução n. 33, de 23 de dezembro de 1992.

BRASIL. Ministério da Saúde. Norma Operacional Básica SUS 01/1991.

BRASIL. Ministério da Saúde. Descentralização das ações e Serviços de Saúde: a ousadia de cumprir e fazer cumprir a lei. Brasília, 1993.

BRASIL. Senado Federal. Constituição da República Federativa do Brasil, 1988.

BENEVIDES, Maria Vitória. Democracia e cidadania. Pólis, Instituto e Assessoria em Políticas Sociais, n. 14, p. 11-19, 1994.

BOBBIO, N. Liberalismo e democracia. São Paulo: Brasiliense, 1988a.

BOBBIO, Norberto; MATTEUCCI, Nicola; PASQUINO, Gianfranco. Dicionário de política. 6. ed. v. 1 e 2. Brasília: Universidade de Brasília, 1994b.

Norberto. Estado, governo e sociedade. Rio de Janeiro: Paz e Terra, 1987c.

O futuro da democracia: uma defesa das regras do jogo. 4. ed. Rio de Janeiro: Paz e Terra, 1989d.

A teoria das formas de governo. Brasília: Ed. Universidade de Brasília, 1980e.

BLOCH, Renata Arruda de. Democratrização da Gestão da Gestões Pública: a muncipalização da saúde nos municípios brasileiros de pequeno e médio porte. Rio de Janeiro, 1999. Dissertação (Mestrado) - FGV-RJ. 150 p.

CARLOS, Ana Fani Alessandri. A (re)produção do espaço urbano. São Paulo: Edusp, 1994.

CALDEIRA, César. Entidades representativas e poder local: a participação social institucionalizada. Archè, Rio de Janeiro v. 1 , n. 2,1992.

CORRÊA, Roberto Lobato. O espaço urbano. 2 São Paulo: Ática, 1993.

DOWBOR, Ladislau. A intervenção dos governos locais no processo de desenvolvimento. In: BAVA, Silvio Caccia. (Org.). Desenvolvimento local, Pólis, n. 25, p. 29-44, 1996.
FALCÃO, Ilka Veras; CARVALHO, Eduardo Maia Freese de; BARRETO, K. Magdala Lima et al. Early cerebrovascular accident: implications in working-age adults assisted by the Brazilian Public Health System. Revista Brasileira da Saúde Materuo Infantil, v. 4, n.1, p. 95-101, jan./mar. 2004.

FIGUEREDO, Jorge Eduardo St. Aubyn de. Comunidade cívica, capital social e conselhos de saúde no Estado do Rio de Janeiro. Dissertação (Mestrado em Saúde Pública) Fundação Oswaldo Cruz, Escola Nacional de Saúde Pública, 2001. 113 p.

FLEURY, Sonia (Org.). Saúde e democracia: a luta do CEBES. São Paulo: Lemos,1997.

GADELHA, Angela Maria Jourdan; COIMBRA JR., Carlos E. A.; STOTZ, Eduardo Navarro et al. The integration of epidemiology and anthropology. História, Ciências, saúde-Manguinhos, v. 6, n. 3, p. 689-705, 2000.

HOUTZAGER, G.; ACHARYA, M. Atores da sociedade civil e atores políticos: participação nas novas políticas democráticas em São Paulo. In: AVRITZER, L. Participação em São Paulo. São Paulo: UNESP, 2004. (no prelo)

INSTITUTO DE SAÚDE. Quantos Brasis? Equidade para alocação de recursos no SUS. Imprensa Oficial de São Paulo, 2002.

JANUZZI, P. M. Considerações sobre o uso, mau uso e abuso dos indicadores sociais na formulação e avaliação de políticas públicas municipais. Revista de Administração Pública, Rio de Janeiro, v. 36, n. 1, p. 51-72. jan./fev. 2002.

JANUZZI, Paulo de Martino. Indicadores sociais no Brasil: conceitos fontes e aplicações. Campinas: Alínea, 2001.

MACHADO M. H. Macro-micro: os novos desafios da sociologia e os efeitos no campo da saúde. In: CANESQUI A. M. (Org.). Dilemas e desafios das ciências sociais na saúde coletiva. São Paulo: Hucitec; Rio de Janeiro: Abrasco.1995. p. 83-93.

MAGALHÃES JR, H. M. Estrutura administrativa: um enfoque necessário para a consolidação do SUS. In: CAMPOS, C. R. et al. Sistema Único de Saúde em Belo Horizonte. São Paulo: Xamã, 1998, p. 177-191.

MAQUIAVEL, N. O príncipe. São Paulo: Martin Claret, 2004.

MARINHO, Alexandre; FAÇANHA, Luís Otávio de F. Programas sociais: efetividade, eficiência e eficácia como dimensões operacionais da avaliação. Rio de Janeiro: IPEA, 2001.

MASSOLO, Alejandra. Em direção às bases: descentralização e município. Revista Espaço e Debate, São Paulo, n. 42, p. 40-45, 1988.

MORAES, A. C. R. de. Ideologias geográficas. 3. ed. São Paulo: Hucitec, 1996.

NETTO,J. S. M. Descentralização e democracia: tópicos para debate. Saúde em Debate, Londrina, n. 3, dez. 1991, 33-39.

SANTOS, Milton. A urbanização brasileira. São Paulo: Hucitec, 1993.

SMITH, Neil. Desenvolvimento desigual. Rio de Janeiro: Bertrand Brasil, 1989. 
RIBEIRO, A. W. R.; GUIMARÃES, R. B. O lugar da participação popular na gestão de saúde: matrizes conceituais...

SOUZA, Marcelo Lopes de. Os orçamentos participativos e sua espacialidade: uma agenda de pesquisa. Terra Livre, São Paulo. n. 15, p. 39-58, 2000.

RIBEIRO, E. A. W. A análise geográfica dos gastos municipais em saúde. Dissertação (Mestrado) - UNESP. Presidente Prudente, 2005. 210 p.
TEIXEIRA, S. M. F. Avaliação comparativa das ações integradas de saúde. Divulgação em Saúde para Debate, Londrina, n. 3, p. 78-81, 1991.

VIANNA, A. Programas sociais: efetividade, eficiência e eficácia como dimensões operacionais da avaliação. Rio de Janeiro: IPEA, 2001. 